\title{
Adiponectin, anthropometric measurements and insulin resistance in adolescence with obesity
}

\author{
Nur Aisiyah Widjaja ${ }^{1,2^{*}}$, Rendi Aji Prihaningtyas ${ }^{1}$, Meta Herdiana Hanindita ${ }^{1}$, \\ Roedi Irawan $^{1}$, IDG Ugrasena ${ }^{1} \&$ Retno Handajani ${ }^{3}$ \\ ${ }^{1}$ Department of Child Health, Dr. Soetomo General Academic Hospital, Faculty of \\ Medicine, Universitas Airlangga, Jl. Mayjen Prof. Dr. Moestopo no 6-8, Surabaya, \\ Indonesia; ${ }^{2}$ Medical Doctoral Program Student, Faculty of Medicine, Universitas \\ Airlangga, J. Mayjen Prof. Dr. Moestopo no 47, Surabaya, Indonesia; ${ }^{3}$ Department \\ of Biochemistry, Faculty of Medicine, Universitas Airlangga, J. Mayjen Prof. Dr. \\ Moestopo no 47, Surabaya, Indonesia
}

\begin{abstract}
Introduction: Obesity in adolescents can cause metabolic syndrome. Insulin resistance increases the risk of metabolic syndrome, which then increases the risk of premature death. Studies about anthropometric measurements and adiponectin levels as early markers of insulin resistance in obese adolescents are still limited. Methods: A cross-sectional study was performed on 59 obese adolescents aged 13-16 years. Obesity was established on the basis of the Centers for Disease Control and Prevention (CDC) curve (2000). Insulin and blood glucose level measurements were carried out using an enzymatic kit. Adiponectin levels were assayed using enzyme-linked immunosorbent assay (ELISA). The relationships between variables were evaluated by correlation analysis using SPSS. Results: Statistical tests showed a positive correlation between waist circumference $(r=0.421 ; p=0.001)$ and Homeostatic Model Assessment of Insulin Resistance (HOMA-IR) ( $r=0.396 ; p=0.002)$. Waist-to-hip ratio (WHR) and waist-to-height ratio (WHtR) had a weak positive correlation with insulin $(r=0.343 ; p=0.008$ and $r=0.311 ; p=0.017)$ and HOMA-IR $(r=0.306 ; p=0.018)$. There was a weak negative correlation between adiponectin and insulin in obese adolescents $(r=-0.278 ; p=0.033)$. Conclusion: Anthropometric measurements (waist circumference, WHR and WHtR) and adiponectin can be used for early detection of insulin resistance and hyperinsulinemia in obese adolescents.
\end{abstract}

Keywords: Adiponectin, insulin, HOMA-IR, adolescents, obesity

\section{INTRODUCTION}

Obesity is a global problem. The number of obese individuals is increasing in Asia (Mazidi et al., 2018). Obesity is associated with various complications, including metabolic syndrome, cardiovascular disease and type 2 diabetes mellitus (Asghar \& Sheikh,
2017). These complications have varied effects, ranging from an increased risk of premature death to a reduction in quality of life (Hirko et al., 2015; Morrison et. al., 2015).

In obesity, an increase in the size of fat cells is associated with inflammatory conditions. Visceral fat plays animportant

\footnotetext{
*Corresponding author: Nur Aisiyah Widjaja

Department of Child Health, Dr. Soetomo General Academic Hospital, Faculty of Medicine, Universitas Airlangga, J1. Mayjen Prof. Dr. Moestopo no 6-8, Surabaya, Indonesia

Tel: (+62)8123073379, E-mail: nuril08@yahoo.com

doi: https://doi.org/10.31246/mjn-2019-0100
} 
role in the production of adipocytokines and other pro-inflammatory cytokines to cause inflammation. Pro-inflammatory cytokines are associated with insulin insensitivity (Asghar \& Sheikh, 2017). Insulin resistance plays a role in the pathogenesis of type 2 diabetes mellitus (Tangvarasittichai, 2015), metabolic syndrome (Banerji, Lam \& Chaiken, 2017) and cardiovascular disease (Ormazabal et al., 2018).

Waist circumference is one of the indices used to assess a person's risk of metabolic syndrome (Prakaschandra \& Naidoo, 2017). The associations of waist circumference, thigh circumference, waist-to-hip ratio (WHR) and waistto-height ratio (WHtR) with insulin resistance have been studied previously. However, most studies were conducted in adult subjects of normal weight (BenitesZapata et al., 2019) or those with type 2 diabetes mellitus (Yoon et al., 2016).

Adiponectin is an adipocytokine known to have anti-inflammatory, antiatherogenic and insulin-sensitising effects (Achari \& Jain, 2017; Orlando et al., 2019). Adiponectin levels are known to decrease in obese adolescents (Orlando et al., 2019). Adiponectin has been studied as a protective factor against complications of obesity, such as diabetes mellitus, metabolic syndrome, hypertension, dyslipidaemia and cardiovascular disease (Sharma, McClung \& Abraham, 2016; Orlando et al., 2019). The protective mechanism of adiponectin has been explained through various adiponectin signalling pathways (Ruan \& Dong, 2016). However, clinical research on adiponectin as a marker of insulin resistance has mostly been conducted in adults and patients with type 2 diabetes mellitus (Aleidi et al., 2015).

Studies on adiponectin and anthropometric measurements as initial markers for detecting insulin resistance in obese adolescents are still limited in developing countries. This study aims to analyse the association of anthropometric measurements and adiponectin levels with fasting glucose, insulin and Homeostatic Model Assessment of Insulin Resistance (HOMA-IR) levels in obese adolescents.

\section{MATERIALS AND METHODS}

\section{Study design}

This was a cross-sectional study conducted on obese adolescents. Respondents were considered obese if their Body Mass Index (BMI) was above the $95^{\text {th }}$ percentile on the Centers for Disease Control and Prevention (CDC) 2000 BMI curve according to age and sex. The inclusion criteria were age 1316 years, obese, and consent obtained from a parent/guardian to participate in the study. Respondents suffering from infections, inflammation, autoimmune diseases, cancer, chronic diseases and endocrine disorders, those who were smokers and who consumed alcohol were excluded from this study. This study was conducted after obtaining ethical approval from the ethics committee of the Dr Soetomo General Academic Hospital, Surabaya (No. 0411/KEPK/ VII/2018).

\section{Physical examinations}

Respondents were examined for weight, height, waist circumference and thigh circumference. Weight was measured using a digital scale (Seca, Germany) accurate to $0.1 \mathrm{~kg}$. Height was measured with a portable stadiometer (Seca, Germany) accurate to $0.1 \mathrm{~cm}$. Body weight was measured with respondents standing straight and not wearing footwear or other accessories. Height was measured from the vertex of the head to the heel with respondents in standing position and not wearing footwear or a hat. BMI was calculated with the 
formula of body weight (kilogrammes) divided by height squared (meter squared) and plotted onto the BMI curve according to age and sex (CDC, 2000). Waist circumference was measured using a tape measure accurate to $0.1 \mathrm{~cm}$ at the midpoint between the lowest rib and the endpoint of the iliac crest upon expiration. Hip circumference was measured using a tape measure at the widest area of the hip at the point of the greatest gluteal protuberance. WHR was calculated as waist circumference $(\mathrm{cm})$ divided by hip circumference (cm). WHtR was calculated as waist circumference $(\mathrm{cm})$ divided by height $(\mathrm{cm})$.

\section{Biochemistry examinations}

Blood measurements were performed, including adiponectin, fasting blood glucose levels, insulin and HOMA-IR. Blood collection was carried out in the morning after a 12-hour fast. Blood was drawn from the vena mediana cubiti. Blood was centrifuged, and the serum was removed and stored at $-70^{\circ} \mathrm{C}$ until an adiponectin examination was performed. The adiponectin examination was carried out using enzyme-linked immunosorbent assay (ELISA) in accordance with manufacturer's instructions. The examination of insulin and fasting blood glucose levels was carried out with an enzymatic kit according to standard procedures.
HOMA-IR was used to describe insulin resistance.

\section{Statistical analysis}

Adiponectin, fasting blood glucose, insulin and HOMA-IR levels were expressed as medians and percentiles due to skewed distributions. A normality test was performed on each variable using the Kolmogorov-Smirnov test. The associations between fasting blood glucose, insulin and HOMA-IR with anthropometric measurements and adiponectin levels were analysed by Pearson's and Spearman's rho correlation. Data analysis was performed using SPSS statistics software version 21.0 .

\section{RESULTS}

In this study, there were 59 obese adolescents aged 13-16 years. A total of $32(54.2 \%)$ adolescents were males and 27 (45.8\%) were females. The median fasting insulin level and HOMA IR value were $16.09 \mathrm{mU} / \mathrm{ml}$ and 2.85 , respectively, in obese adolescents (Table 1).

A weak positive correlation was obtained between waist circumference $(r=0.421 ; \quad p=0.001)$ and HOMA-IR $(r=0.396 ; p=0.002)$. WHtR also had a weak positive correlation with HOMA-IR $(r=0.306 ; p=0.018)$ (Table 2). WHR and

Table 1. Characteristics of obese adolescents

\begin{tabular}{lc}
\hline Variable & Median $\left(25^{\text {th }}-75^{\text {th }}\right)$ \\
\hline Body Mass Index $\left(\mathrm{kg} / \mathrm{m}^{2}\right)$ & $31.25(29.20-33.70)$ \\
Waist circumference $(\mathrm{cm})$ & $97.20(94.00-107.00)$ \\
Hip circumference $(\mathrm{cm})$ & $105.00(99.00-110.00)$ \\
WHR & $0.95(0.91-0.99)$ \\
WHtR & $0.62(0.59-0.66)$ \\
Adiponectin $(\mathrm{ng} / \mathrm{ml})$ & $6841.90(5204.66-10044.31)$ \\
Fasting blood glucose $(\mathrm{mg} / \mathrm{dl})$ & $79.00(75.00-84.00)$ \\
Insulin $(\mathrm{mU} / \mathrm{ml})$ & $16.09(10.87-22.82)$ \\
HOMA-IR & $2.85(2.07-4.24)$ \\
\hline
\end{tabular}

$25^{\text {th }}:$ percentile $25 ; 75^{\text {th }}:$ percentile 75

WHR: Waist-to-hip ratio; WHtR: Waist-to-height ratio; HOMA-IR: Homeostatic Model Assessment of Insulin Resistance 
Table 2. Correlation between anthropometric measurements and insulin resistance

\begin{tabular}{lcccccc}
\hline Variable & \multicolumn{2}{c}{ Fasting blood glucose } & \multicolumn{2}{c}{ Insulin } & \multicolumn{2}{c}{ HOMA-IR } \\
\cline { 2 - 7 } & $r$ & $p$ & $r$ & $p$ & $r$ & $p$ \\
\hline Body Mass Index $^{\ddagger}$ & 0.168 & -0.182 & 0.111 & 0.401 & 0.068 & 0.608 \\
Waist circumference $^{\dagger}$ & 0.029 & 0.830 & 0.421 & $0.001^{*}$ & 0.396 & $0.002^{*}$ \\
Hip circumference & -0.094 & 0.480 & 0.034 & 0.276 & 0.152 & 0.251 \\
WHR $^{\ddagger}$ & 0.105 & 0.213 & 0.343 & $0.008^{*}$ & 0.159 & 0.230 \\
WHtR $^{\dagger}$ & 0.108 & 0.416 & 0.311 & $0.017^{*}$ & 0.306 & $0.018^{*}$ \\
\hline
\end{tabular}

†Spearman's rho correlation

*Pearson's correlation

*significant at $p<0.05$

WHR: Waist-to-hip ratio; WHtR: Waist-to-height ratio

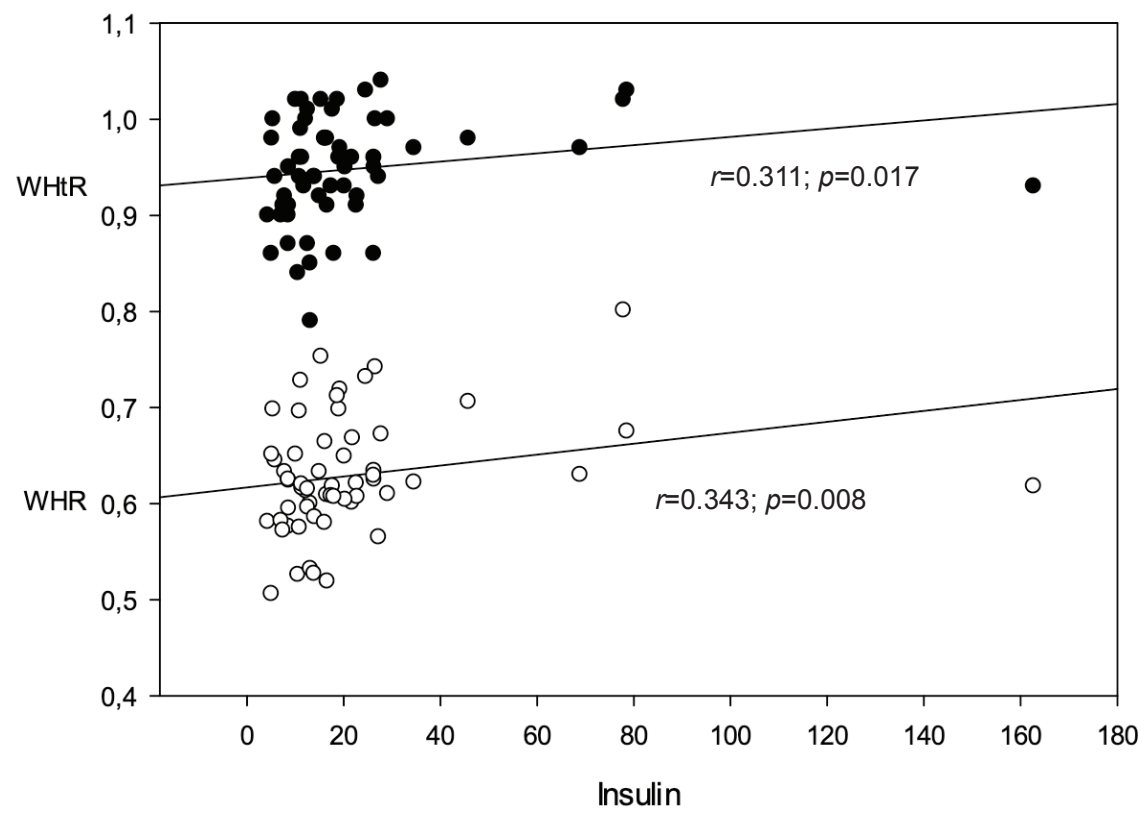

Figure 1. Correlation of insulin with WHR and WHtR

WHtR had a weak positive correlation with insulin $(r=0.343 ; p=0.008 ; r=0.311$; $p=0.017$ ) (Figure 1).

There was a weak negative correlation between adiponectin and insulin levels $(r=-0.278 ; \quad p=0.033)$. Statistical tests did not detect a relationship between adiponectin and HOMA-IR or fasting blood glucose levels ( $p>0.05)$ (Table 3). In this study, a negative correlation was found between adiponectin and insulin levels (Figure 2).

\section{DISCUSSION}

Pro-inflammatory cytokines are associated with various metabolic complications, such as insulin resistance (Asghar \& Sheikh, 2017). As chronic, low-level inflammation occurs in obesity, it is therefore associated with insulin resistance (Lim et al., 2015). There is an increase in fasting insulin levels and HOMA-IR in obese adolescents. HOMAIR is an index of peripheral insulin sensitivity, which is used to predict 
Table 3. Correlation between adiponectin and insulin resistance

\begin{tabular}{lcc}
\hline \multicolumn{1}{c}{ Variable } & \multicolumn{2}{c}{ Adiponectin } \\
\cline { 2 - 3 } & $r$ & $p$ \\
\hline Fasting blood glucose $^{\ddagger}$ & 0.036 & 0.789 \\
Insulin $^{\dagger}$ & -0.278 & $0.033^{*}$ \\
HOMA-IR $^{\ddagger}$ & -0.205 & 0.119 \\
\hline
\end{tabular}

†Spearman's rho correlation

*Pearson's correlation

*significant at $p<0.05$

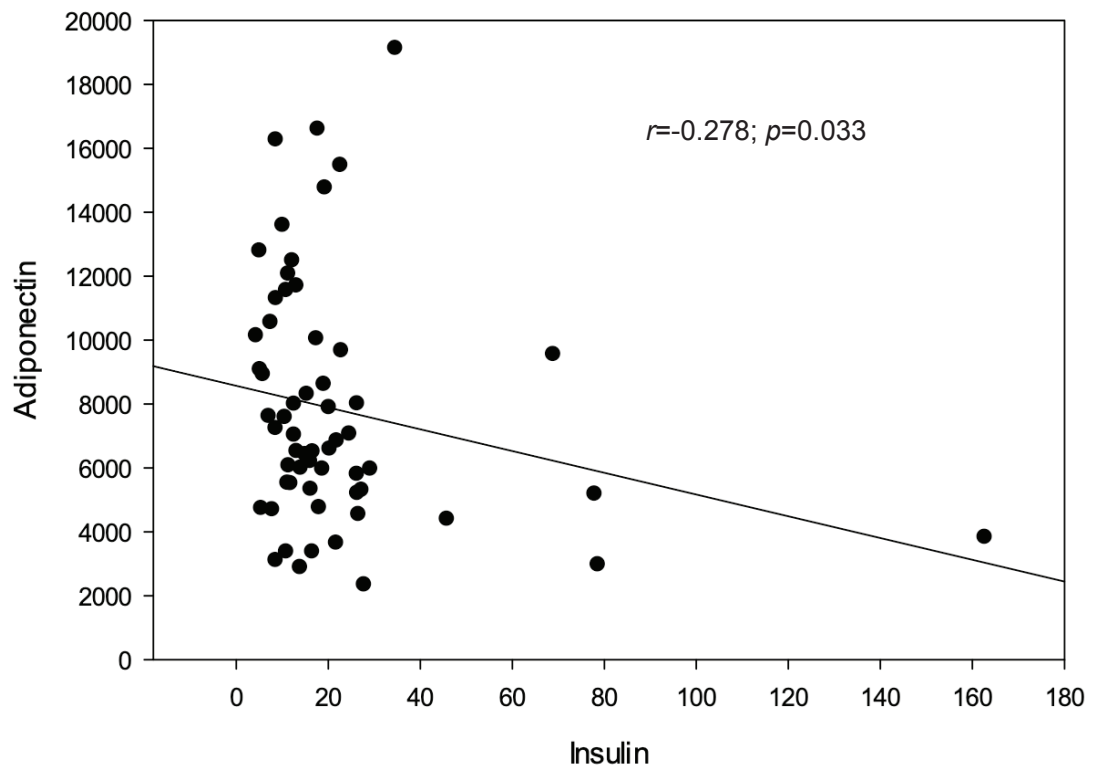

Figure 2. Correlation between adiponectin and insulin

insulin resistance. Increased HOMA-IR is accompanied by increased levels of blood glucose, low-density lipoprotein cholesterol, triglycerides, insulin and glycated haemoglobin (HbA1c), which are risk factors for metabolic syndrome (González-Jiménez et al., 2016). BMI is associated with insulin secretion and insulin sensitivity in obesity (Wang et al., 2016). An increase in HOMA-IR is proportional to an increase in the BMI of adolescents (González-Jiménez et al., 2016), although this increase can also be found in healthy adolescents (Telford et al., 2012). In this study, there was no relationship between BMI and fasting blood glucose levels, insulin or insulin resistance. The findings of this study differed from those of previous studies which showed BMI to be correlated with insulin resistance (Cheng et al., 2017; González-Jiménez et al., 2016; Lim et al., 2015). However, the strength of correlation between BMI with insulin resistance shown by HOMA-IR was found to be weak in adolescents (Convit, Wedin \& Diaz-Gimenez, 2012).

Body fat composition has a larger effect on insulin resistance than body fat percentage (Cheng et al., 2017). In this study, waist circumference and WHtR were positively correlated with insulin and HOMA-IR. Previous studies have suggested that waist circumference is 
correlated with increased insulin levels (Cempaka \& Sidiartha, 2017) and HOMAIR (da Silva et al., 2018; Lim et al., 2015). Waist circumference is more strongly correlated with HOMA-IR than with BMI (Convit et al., 2012). In a similar study, adolescents stated that BMI, along with increased waist circumference and systolic blood pressure, were risk factors for insulin resistance (González-Jiménez et al., 2016).

This study found that WHR has a positive correlation with insulin, similar to studies conducted in China. A study on respondents with normal weight showed that WHR was associated with hyperinsulinemia after tests of glucose tolerance and insulin resistance (BenitesZapata et al., 2019). Hyperinsulinemia in obesity occurs due to compensatory insulin secretion under conditions of insulin resistance (Wang et al., 2016). WHR has also been shown to have a positive correlation with HOMA-IR (Lim et al., 2015). However, in this study, there was no relationship between WHR and HOMA-IR. One possible explanation may be the similarities in pancreatic beta-cell function disorders between obese and non-obese respondents with impaired glucose tolerance (Takahara et al., 2013).

Adiponectin is produced by fat tissue. The concentration of adiponectin in plasma is $2-30 \mu \mathrm{g} / \mathrm{ml}$ (Sharma et al., 2016). Although adiponectin is produced by fat tissue, but its level is decreased in obesity. Adiponectin is negatively correlated with metabolic syndrome (Ntzouvani et al., 2016), prevents cardiovascular disease and improves insulin sensitisation (Stern, Rutkowski \& Scherer, 2016). In this study, low levels of adiponectin were obtained. Adiponectin had no correlation with blood glucose and HOMA-IR levels, but had a negative correlation with fasting insulin levels.
The differences between our results and those of previous studies may have been due to several factors. The relationship between anthropometric measurements and insulin resistance can vary between study populations, influenced by ethnicity (Yoon et al., 2016) and age (Chandler-Laney et al., 2010). Similarly, adiponectin levels are also influenced by ethnicity and gender (Sharma et al., 2016; Aleidi et al., 2015). However, combinations of anthropometric measurements can be used to predict cardiometabolic risk in adolescents (Samouda et al., 2015). In addition, adiponectin and anthropometric measurements are also useful for early detection of insulin resistance and hyperinsulinemia in obese adolescents.

This study has several limitations. Firstly, the sample size was limited and there were no non-obese subjects with normal BMI included as a comparison group in this study. Secondly, no serial measurements of adiponectin, blood glucose and insulin levels were performed in this study. This could have affected the accuracy of the results as blood glucose can be affected by dietary consumption and physical activity.

\section{CONCLUSION}

There was a positive correlation in waist circumference, WHR and WHtR with insulin, while a positive correlation was observed between waist circumference and WHtR with HOMA-IR. There was no correlation between adiponectin and blood glucose levels or HOMA-IR. Adiponectin had a negative correlation with fasting insulin levels. Adiponectin, waist circumference, WHR and WHtR can be used for early detection of insulin resistance and hyperinsulinemia in obese adolescents. This can be one step towards preventing metabolic syndrome in adulthood. 


\section{Acknowledgement}

The authors thank Universitas Airlangga and Dr. Soetomo Academic General Hospital, Surabaya, Indonesia for supporting this research.

\section{Authors' contributions}

NAW, principal investor, conceptualised and designed the study, prepared the draft of the manuscript and reviewed the manuscript; RAP, led the data collection, data analysis and wrote the manuscript; $\mathrm{MHH}$, reviewed the manuscript; RI, led the data collection and reviewed the manuscript; IDGU, reviewed the manuscript; $\mathrm{RH}$, reviewed the manuscript.

\section{Conflict of interest}

The authors declare no conflict of interest in this study.

\section{References}

Aleidi S, Issa A, Bustanji H, Khalil M \& Bustanji Y (2015). Adiponectin serum levels correlate with insulin resistance in type 2 diabetic patients. Saudi Pharm J 23(3):250-256. https://doi. org/10.1016/j.jsps.2014.11.011

Achari AE \& Jain SK (2017). Adiponectin, a Therapeutic Target for Obesity, Diabetes, and Endothelial Dysfunction. Int $J \mathrm{Mol}$ Sci 18(6):1321-1338. https://doi.org/10.3390/ ijms 18061321

Asghar A \& Sheikh N (2017). Role of immune cells in obesity induced low grade inflammation and insulin resistance. Cell Immunol 315:18-26. https://doi.org/10.1016/j. cellimm.2017.03.001

Banerji MA, Lam ML \& Chaiken R (2017). Insulin Resistance and the Metabolic Syndrome. In L Poretsky (Ed.), Principles of Diabetes Mellitus (pp. 1-25). https://doi.org/10.1007/978-3319-20797-1_34-2

Benites-Zapata VA, Toro-Huamanchumo CJ, Urrunaga-PastorD, Guarnizo-Poma M, Lazaro-Alcantara H, Paico-Palacios S, Pantoja Torres B \& Ranilla-Seguin V del C. (2019). High waist-to-hip ratio levels are associated with insulin resistance markers in normalweight women. Diabetes Metab Syndr: Clinical Research \& Reviews 13(1):636-642. https:// doi.org/10.1016/j.dsx.2018.11.043

Cempaka VP \& Sidiartha IGL (2017). Waist circumference and insulin levels in obese children. Paediatr Indones 57(4):194-197. https: / / doi.org/ 10.14238/pi57.4.2017.194-7
CDC (2000). Clinical Growth Charts. Children 2-20 years: BMI-for-age. Centers for Disease Control and Prevention (CDC) and the National Center for Health Statistics, Maryland. From https:// www.cdc.gov/growthcharts/cdc_charts.htm. [Retrieved December 10 2019].

Chandler-Laney PC, Phadke RP, Granger WM, Muñoz AJ, Dalla Man C, Cobelli C. Ovalle F, Fernández JR \& Gower BA (2010). Adiposity and $\beta$-cell function: relationships differ with ethnicity and age. Obesity (Silver Spring) 18(11): 2086-2092. https://doi.org/10.1038/ oby. 2010.44 .

Cheng YH, Tsao YC, Tzeng IS, Chuang HH, Li WC, Tung TH \& Chen JY (2017). Body mass index and waist circumference are better predictors of insulin resistance than total body fat percentage in middle-aged and elderly Taiwanese: Medicine 96(39): e8126. https:// doi.org/ 10.1097/MD.0000000000008126

Convit AJ, Wedin KW \& Diaz-Gimenez L (2012). Prediction of insulin resistance with anthropometric measures: Lessons from a large adolescent population. Diabetes Metab Syndr Obes: Targets and Therapy 5:219-225. https://doi.org/10.2147/DMSO.S33478

da Silva CC, Vasques ACJ, Zambon MP, Camilo DF, De Bernardi Rodrigues AM, Antonio MÂRGM \& Geloneze B (2018). Sagittal abdominal diameter resembles waist circumference as a surrogate marker of insulin resistance in adolescentsBrazilian Metabolic Syndrome Study. Pediatr Diabetes 19(5):882-891. https://doi. org/10.1111/pedi. 12664

González-Jiménez E, Schmidt-RioValle J, MonteroAlonso MA, Padez C, García-García CJ \& Perona JS (2016). Influence of Biochemical and Anthropometric Factors on the Presence of Insulin Resistance in Adolescents. Biol Res Nurs 18(5):541-548. https://doi. org/10.1177/1099800416648207

Hirko KA, Kantor ED, Cohen SS, Blot WJ, Stampfer MJ \& Signorello LB (2015). Body Mass Index in Young Adulthood, Obesity Trajectory, and Premature Mortality. Am $J$ Epidemiol 182(5):441-450. https://doi.org/10.1093/aje/ kwv084

Lim SM, Choi DP, Rhee Y \& Kim HC (2015). Association between Obesity Indices and Insulin Resistance among Healthy Korean Adolescents: The JS High School Study. PLOS ONE 10(5):e0125238. https://doi. org/10.1371/journal.pone.0125238 
Mazidi M, Banach M, Kengne AP \& Meta-analysis Collaboration Group (2018). Prevalence of childhood and adolescent overweight and obesity in Asian countries: A systematic review and meta-analysis. Arch Med Sci 14(6):11851203.

Morrison KM, Shin S, Tarnopolsky M \& Taylor VH (2015). Association of depression \& health related quality of life with body composition in children and youth with obesity. J Affect Disord 172:18-23. https://doi.org/10.1016/j. jad.2014.09.014

Ntzouvani A, Fragopoulou E, Panagiotakos D, Pitsavos C \& Antonopoulou S (2016). Reduced circulating adiponectin levels are associated with the metabolic syndrome independently of obesity, lipid indices and serum insulin levels: A cross-sectional study. Lipids Health Dis 15(1):1-14. https://doi.org/10.1186/s12944016-0311-7

Orlando A, Nava E, Giussani M \& Genovesi S (2019). Adiponectin and Cardiovascular Risk. From Pathophysiology to Clinic: Focus on Children and Adolescents. Int $J$ Mol Sci 20(13):1-14. https://doi.org/10.3390/ijms20133228

Ormazabal V, Nair S, Elfeky O, Aguayo C, Salomon C \& Zuñiga FA (2018). Association between insulin resistance and the development of cardiovascular disease. Cardiovasc Diabetol 17(1):1-14. https://doi.org/10.1186/s 12933018-0762-4

Prakaschandra R \& Naidoo DP (2017). Increased waist circumference is the main driver for the development of the metabolic syndrome in South African Asian Indians. Diabetes Metab Syndr: Clinical Research \& Reviews 11:S81-S85. https://doi.org/10.1016/j. dsx.2016.12.011

Ruan H \& Dong LQ (2016). Adiponectin signaling and function in insulin target tissues. $\mathrm{J} \mathrm{Mol} \mathrm{Cell}$ Biol 8(2):101-109. https://doi.org/10.1093/ $\mathrm{jmcb} / \mathrm{mjw} 014$

Samouda H, de Beaufort C, Stranges S, Guinhouya BC, Gilson G, Hirsch M, Jacobs J, Leite S, Vailant M \& Dadoun F (2015). Adding anthropometric measures of regional adiposity to BMI improves prediction of cardiometabolic, inflammatory and adipokines profiles in youths: A cross-sectional study. BMC Pediatr 15(1):1-9. https://doi.org/10.1186/s12887015-0486-5
Sharma M, McClung JA \& Abraham NG (2016). Chapter 4 - Adiponectin: A Mediator of Obesity, Insulin Resistance, Diabetes, and the Metabolic Syndrome. In Translational Research in Coronary Artery Disease (pp. 33-42). https: / / doi.org/ 10.1016/B978-0-12-8023853.00004-8

Stern JH, Rutkowski JM \& Scherer PE (2016). Adiponectin, Leptin, and Fatty Acids in the Maintenance of Metabolic Homeostasis through Adipose Tissue Crosstalk. Cell Metab 23(5):770-784. https://doi.org/10.1016/j. cmet.2016.04.011

Takahara M, Katakami N, Kaneto H, Noguchi M \& Shimomura I (2013). Pancreatic beta cell function in lean and obese Japanese with various degrees of glucose tolerance. Endocr $J$ 60(7):923-930. https://doi.org/10.1507/ endocrj.EJ13-0046

Tangvarasittichai S (2015). Oxidative stress, insulin resistance, dyslipidemia and type 2 diabetes mellitus. World $J$ Diabetes 6(3):456. https://doi.org/10.4239/wjd.v6.i3.456

Telford RD, Cunningham RB, Telford RM, Kerrigan J, Hickman PE, Potter JM \& Abhayaratna WP (2012). Effects of Changes in Adiposity and Physical Activity on Preadolescent Insulin Resistance: The Australian LOOK Longitudinal Study. PLoS ONE 7(10):e47438. https://doi. org/10.1371/journal.pone.0047438

Wang T, Ma X, Tang T, Jin L, Peng D, Zhang R, Chen M, Yan J, Wang S, Yan D, He Z, Jiang F, Cheng X, Bao Y, Liu Z, Hu C \& Jia W (2016). Overall and central obesity with insulin sensitivity and secretion in a Han Chinese population: A Mendelian randomization analysis. Int $J$ Obes 40(11):1736-1741. https://doi.org/10.1038/ ijo.2016. 155

Yoon YS, Choi HS, Kim JK, Kim YI \& Oh SW (2016). Differences in the associations of anthropometric measures with insulin resistance and type 2 diabetes mellitus between Korean and US populations: Comparisons of representative nationwide sample data. Obes Res Clin Pract 10(6):642-651. https://doi. org/10.1016/j.orcp.2015.11.001 